March 2014

\title{
Examining cohort differences and resilience among the aging LGBT community: Implications for education and practice among an expansively diverse population
}

\author{
Michael P. Dentato \\ Loyola University Chicago, mdentato@luc.edu \\ John Orwat \\ Loyola University Chicago, jorwat@luc.edu \\ Marcia K. Spira \\ Loyola University Chicago, jorwat@luc.edu
}

Benjamin Walker

Howard Brown Health Center, benjaminwalkermsw@gmail.com

Follow this and additional works at: https://ecommons.luc.edu/social_justice

Part of the Social Work Commons

\section{Recommended Citation}

Dentato, Michael P.; Orwat, John; Spira, Marcia K.; and Walker, Benjamin, "Examining cohort differences and resilience among the aging LGBT community: Implications for education and practice among an expansively diverse population" (2014). Social Justice. 50.

https://ecommons.luc.edu/social_justice/50

This Article is brought to you for free and open access by the Centers at Loyola eCommons. It has been accepted for inclusion in Social Justice by an authorized administrator of Loyola eCommons. For more information, please contactecommons@luc.edu. 
This article was downloaded by: [Loyola University Libraries]

On: 30 March 2014, At: 07:08

Publisher: Routledge

Informa Ltd Registered in England and Wales Registered Number: 1072954 Registered office: Mortimer House, 37-41 Mortimer Street, London W1T 3J H, UK

Human Behavior

in the Social

Environment

\section{J ournal of Human Behavior in the Social Environment}

Publication details, including instructions for authors and subscription information:

http:/ / www.tandfonline.com/loi/ whum20

\section{Examining Cohort Differences and Resilience among the Aging LGBT Community: Implications for Education and Practice among an Expansively Diverse Population}

Michael P. Dentato ${ }^{a}$, J ohn Orwat ${ }^{a}$, Marcia Spira ${ }^{a} \&$ Benjamin Walker ${ }^{b}$

a School of Social Work, Loyola University, Chicago, Illinois, USA

${ }^{b}$ Howard Brown Health Center, Chicago, Illinois, USA

Published online: 25 Mar 2014.

To cite this article: Michael P. Dentato, J ohn Orwat, Marcia Spira \& Benjamin Walker (2014) Examining Cohort Differences and Resilience among the Aging LGBT Community: Implications for Education and Practice among an Expansively Diverse Population, Journal of Human Behavior in the Social Environment, 24:3, 316-328, DOI: 10.1080/10911359.2013.831009

To link to this article: http:// dx.doi.org/10.1080/ 10911359.2013.831009

\section{PLEASE SCROLL DOWN FOR ARTICLE}

Taylor \& Francis makes every effort to ensure the accuracy of all the information (the "Content") contained in the publications on our platform. However, Taylor \& Francis, our agents, and our licensors make no representations or warranties whatsoever as to the accuracy, completeness, or suitability for any purpose of the Content. Any opinions and views expressed in this publication are the opinions and views of the authors, and are not the views of or endorsed by Taylor \& Francis. The accuracy of the Content should not be relied upon and should be independently verified with primary sources of information. Taylor and Francis shall not be liable for any losses, actions, claims, proceedings, demands, costs, expenses, damages, and other liabilities whatsoever or howsoever caused arising directly or indirectly in connection with, in relation to or arising out of the use of the Content.

This article may be used for research, teaching, and private study purposes. Any substantial or systematic reproduction, redistribution, reselling, loan, sub-licensing, systematic supply, or distribution in any form to anyone is expressly forbidden. Terms \& 


\title{
Examining Cohort Differences and Resilience among the Aging LGBT Community: Implications for Education and Practice among an Expansively Diverse Population
}

\author{
Michael P. Dentato, John Orwat, and Marcia Spira \\ School of Social Work, Loyola University, Chicago, Illinois, USA \\ Benjamin Walker \\ Howard Brown Health Center, Chicago, Illinois, USA
}

\begin{abstract}
The aging lesbian, gay, bisexual, and transgender (LGBT) community continues to grow considerably while often being faced with unique and unmet needs separate from younger LGBT cohorts or their non-LGBT counterparts. This article explores some of the differences in attitudes among generational cohort groups regarding coming out decisions; sexual risk and safety; the impact of evolving policies within systems and society; as well as the demonstrated strengths and resiliencies of the aging LGBT community. Implications and suggestions for education, training, and best practices among this expansive and diverse population are considered as well as continued research in the field of LGBT aging.
\end{abstract}

Keywords: LGBT, aging, generational cohorts, diversity, practice, education, training

\section{INTRODUCTION}

An emergent dialogue grows among researchers, practitioners and educators with regard to the examination of best practices and affirming models of care for members of the aging lesbian, gay, bisexual, and transgender (LGBT) community. This dialogue often includes the reexamination of societal views on the aging process itself, as members of older and aging communities are routinely oppressed, stigmatized, and invisible (Shankle, Maxwell, Katzman, \& Landers, 2003). Subgroups experiencing even greater forms of such invisibility exist among the aging LGBT population. In fact, the lived experiences of LGBT members of the "Greatest" generation (born 1900-1920) and post-WWII "Baby Boom" generation (born 1946-1964) re-tell a long history of societal marginalization by sociopolitical influences; and voluntary choices some individuals made consciously to conceal their sexual orientation or gender identity and remain invisible as a matter of self-protection and safety (Clunis, Fredriksen-Goldsen, Freeman, \& Nystrom, 2005).

Address correspondence to Michael P. Dentato, School of Social Work, Loyola University, 820 North Michigan Avenue, Chicago, IL 60611, USA. E-mail: mdentato@luc.edu 
Regardless of the broadening acceptance of LGBT issues over the past 40 years, many LGBT older adults continue to experience a number of significant obstacles and challenges, while a large number have been denied services on the basis of sexual orientation or gender identity (Fredricksen-Goldsen et al., 2011). Other factors including race, class, socioeconomic status, and HIV status may compound external barriers to health and mental health care, while personal experiences of discrimination may lead to a mistrust of such professions, creating even more care-seeking barriers (Hughes, Harold, \& Boyer, 2011). For many of these reasons, approximately $21 \%$ of older LGBT adults are not out of the closet (Fredricksen-Goldsen \& Muraco, 2010). Some have kept their identities hidden for a long time, while others have been forced back into the closet as they enter assisted living, housing, or health care situations perceived to be unwelcoming or hostile. Additionally, U.S. federal, state, and local policies are inconsistent in protecting older LGBT adults and their partners from discrimination in the areas of healthcare, caregiving, housing, and finance (SAGE, 2013). Among such barriers to care, LGBT age cohort differences exist that may isolate members from one another and from larger mainstream LGBT culture. While many have found ways to overcome some of these barriers through coping, adaptation, and resilience (Butler, 2004), others have remained silent about their ongoing struggles. All of these factors are compounded by caregiving systems and mental health professionals that lack competency and education about LGBT aging issues (Hughes et al., 2011).

Examining such factors through a life course perspective (Bronfenbrenner, 1979) may best assist with understanding the profound impact of differences among generational age cohorts (Wethington, 2005) along with implications for well aging among LGBT older adults. Knowledge and understanding of an individual's prior life course is essential to best understand the breadth and depth of the later years of aging (Elder, 1994). Developmental processes and outcomes are uniquely shaped by social trajectories along the life span, with implications related to early choices and decision making (Eckenrode \& Gore, 1990; Moen, Dempster-McClain, \& Williams, 1992). Common components of the life course perspective include the interplay of life and historical times, the timing of lives, linked or interdependent lives, and human agency utilized in decisionmaking processes (Bronfenbrenner, 1979; Elder, 1994). It is therefore relevant to continue research and a dialogue about application of such components related to the life course perspective when examining older LGBT adults and generational cohort differences related to health, risk behaviors, perceptions of well aging, and how these concepts change over time (Wethington, 2005). This article will explore such unique challenges and opportunities facing the aging LGBT community through a life course perspective, including age cohort differences, and conclude with implications for practitioners and educators surrounding opportunities and best practices in the field.

\section{BACKGROUND}

It is estimated that among the general aging population, the total number of older LGBT individuals ranges somewhere between 1 to 3.5 million people (Shankle et al., 2003) and will grow considerably with the retiring baby boom population over the upcoming decades. In general, by the year 2030, the number of adults 65 and older will increase dramatically, representing almost $20 \%$ of the population (U.S. Census Bureau, 2010). At that time, between 2 and 6 million LGBT adults will be 65 years of age and older (SAGE, 2013; Fredriksen-Goldsen et al., 2010). A unique set of challenges continue to face the aging LGBT community, including those surrounding physical and mental health, housing, caregiving, sex and sexuality, legal matters, substance use and addiction, among other areas (Grossman, 2006). However, to better understand the well aging needs of the LGBT community, it may be prescient to explore perceptions and differences among pre- and post-Stonewall age cohorts within the LGBT community. 


\section{Socio-Historical Relevance}

There have been significant historical, social, cultural, and legal changes over the past four decades following three nights of protest and civil unrest during the summer of 1969 in New York City at the Stonewall Inn (Spencer, 1995). It remains important to examine and understand LGBT older adults in such contexts as the historical and social realms (Fredriksen-Golden et al., 2010; Clunis et al., 2005) and take into account the culture, politics, and social mores of the era in which they came of age to best understand their uniquely lived experiences and needs. Prior to the significant social and legislative changes that followed the Stonewall uprising, homosexuality had been pathologized in the American Psychiatric Association's Third Diagnostic and Statistical Manual of Mental Disorders (DSM-III) as a mental disorder, compounded by anti-gay legislation and social propaganda resulting in LGBT individuals risking job loss, family separation, social standing, and potentially even personal safety (Atkins, 2003; Williams \& Freeman, 2007; Weststrate \& McLean, 2010).

After World War II, most states recognized homosexuality as a socially threatening disease (Messinger, 2006, p. 25), and experimental treatment procedures included shock therapy, lobotomy, and genital mutilation. During this time, homosexuality was often connected with treason and Communism, including dismissal of many government employees and police raids on gay bars, resulting in the humiliating publication of detainees' names in military reports and local newspapers (Messinger, 2006). As recent as 1998, sodomy laws criminalized same-sex acts and were used to discriminate against and marginalize members of the LGBT community before such laws were struck down in most states (Elze, 2006). Though the uprising at Stonewall ushered in an era of increased visibility and activism for members of the LGBT community over the past 40 years, the event itself, along with precipitating psychosocial factors, has had a profound effect upon the identities and lives of older LGBT adults (Vaccaro, 2009; Weststrate \& McLean, 2010). This has not only affected the physical and mental health of many generations of LGBT individuals but also impacts the manner in which they seek care. Ultimately, such lived experiences may differ significantly for members of the aging LGBT community, when compared to their non-LGBT counterparts, thus providing a unique opportunity for continued research from the life-course perspective.

\section{Life Span Identity Development and Age Cohorts}

It may be prescient to examine LGBT identity development, specifically sexual identity development, as offering another focus of aging shaped by social and historical contexts relevant to the LGBT community and culture. LGBT individuals often do not experience the same transitions that exist over the duration of the life course as their heterosexual counterparts. Understanding the implications of such differences is essential to assess the interactions between individuals, social groups, and changing social structures and contexts (Fredriksen-Golden et al., 2010). Among literature exploring birth cohort (Parks, 1999; Rosenfeld, 1999) differences and maturational factors, it remains evident that the larger social context (Floyd \& Bakeman, 2006), plays a significant role in sexual identity development. Dividing older LGBT adults into age groups or identity cohorts (Parks, 1999; Rosenfeld, 1999) provides insight with regard to differing perspectives on the need for advocacy, issues related to social justice (employment, housing, relationships, etc.), and the discrepant perceptions of disclosure management related to coming out or remaining closeted. Rosenfeld's study (1999) divided participants into a pre-Stonewall cohort (defined as a more passively silent group stigmatized by homosexuality); and a post-Stonewall cohort (which viewed homosexuality as a status imbued with political and moral meanings). Such membership in identity cohorts may introduce intra-generational, inter-cohort tensions to social worlds in which inter-generational tensions already exist, causing identity cohort members to be 
estranged not only from members of other generations but from certain members of their own (Rosenfeld, 1999).

In the same regard, Vaccaro's 2009 study discovered that "Baby Boomers" and Generation "Xers" (born 1960s-1980s) identified stark differences between "Millennials" (born 1980s-2000s) and their own lived experiences surrounding factors related to coming out, family relationships, activism, prejudice, and experiences of discrimination. In fact, differences might exist within the same age cohort among two individuals who experience similar historical events with divergent reactions based on geography, race, socioeconomic status and other factors Fullmer (2006). Such an examination of age cohort similarities and differences is essential for understanding best practices and service provision as well as ongoing research in the field of LGBT aging. Myriad factors impact an LGBT individual's lived experiences, perceptions of support, expectations for acceptance or rejection, as well as the ability to develop resilience (Butler, 2004) and an ability to cope and adapt. In addition to cohorts managing such aforementioned stressors differently is the potential for perceived or actual experiences of discrimination, harassment, or prejudice within the LGBT community itself (Meyer, 1995, 2003). Throughout history, tension between subgroups in the LGBT community has been apparent; lesbians were excluded from gay organizations; transwomen were expelled from lesbian organizations; bisexuals were excluded from the broader gay and lesbian movements; class divisions went mostly overlooked; and men and women of all kinds were excluded from a variety of groups on the basis of being too visibly "butch" or "femme" (Messinger, 2006).

In the same regard, despite the increasing presence of actors and politicians becoming public about their positive association as allies or openly as members of the LGBT community, ageism is much more visible. Most LGBT stereotypical character depiction is that of young, handsome and virile adults. The few older LGBT figures who become more public are typically successful, famous and well respected due to their public accomplishments. Despite Vaccaro's (2009) study finding that more intergenerational similarities existed than each cohort might expect, it is clear that the older generations of LGBT adults may feel somewhat devalued by, estranged from or invisible to both mainstream LGBT society and society as a whole.

Remaining continually isolated and quite invisible (Reid, 1995) for a large part of one's life course is an important influence to consider with regard to understanding implications for differing age cohort perceptions (Elder, 1994) of self-identity, access, privilege and power (Van Wagenen, Driskell, \& Bradford, 2013). In spaces where LGBT supportive attitudes are not readily expressed, many older LGBT individuals may feel the need to conceal their identity - or go back into the closet-even after years of living "out," for fear of discrimination (Persson, 2009; Stein, Beckerman, \& Sherman, 2010). With this comes great emotional stress as LGBT individuals may struggle in silence, whether situational (i.e., unable to grieve the loss of a loved one), coping with traumatic events, or when incapable of sharing memories with others (Stein et al., 2010). Additionally, bearing such stress over time may increase the potential for risk behavior related to substance use, sexual health, and suicide ideation or attempt, among other factors (Elze, 2006; Logie, Bridge, \& Bridge, 2007). Notably, many members of the LGBT community rely upon various circles of friends, allies, and families of "choice" or origin to provide elements of support throughout the grief or coping process. In addition to stressors associated with identifying as LGBT lies the intersection or affiliation with other identities (i.e., race, gender identity, disability, etc.). Such multiple identities might impact chronic stressors such as oppression and discrimination or potentially amplify risks associated with acute stressors including victimization or hate crimes (Elze, 2006). Alone, such risks are significant enough, but recent research continues to emphasize the relationship between poor mental health and physical health outcomes (Fredricksen-Golden et al., 2011). Thus, care for the aging LGBT community must be competent and keenly aware of a multitude of LGBT aging issues, as practitioners could risk overlooking key factors that would critically enhance their work among this population. 


\section{HEALTH AND MENTAL HEALTH: UNDERSCORING STRENGTHS AND RESILIENCE}

When examining the struggles faced by LGBT older adults, it is important to understand that while these experiences may have been difficult or painful for many, they do not always result in continued suffering or pathology. Such assumptions of associated pathology are problematic and offer limited insight related to the many positive and affirming aging experiences of LGBT adults and other vulnerable communities (Logie et al., 2007; Fredricksen-Goldsen et al., 2010). This is clearly evidenced in earlier literature and research describing positive psychosocial functioning among older gay men and lesbians (Berger, 1984; Gray \& Dressel, 1985; Berger \& Kelly, 1986), with favorable feelings about aging (Whitford, 1997), appearance (Gray \& Dressel, 1985), and sexuality (Pope \& Schulz, 1990). Subsequent studies found older gay male and lesbian adults to be no more depressed than their heterosexual counterparts (Dorfman et al., 1995), and a majority of gay and lesbian adults notably rate their mental health as excellent or good (D'Augelli \& Grossman, 2001). Though social discrimination, homophobia, and ageism can have negative effects on older LGBT adults, such limitations have underscored a multitude of coping mechanisms and resilience (Butler, 2004) for members of this often oppressed community (Smith, McCaslin, Chang, Martinez, \& McGrew, 2010). In light of overwhelming social and political discrimination, members of the LGBT community from the "Greatest" and "Baby Boom" generations were particularly active in fighting for equality and the rights of the modern LGBT movement (Messinger, 2006). Additionally, while some members of the LGBT community face rejection from their families of origin, many are adept at developing their own psychosocial support systems (Cohen, Padilla, \& Aravena, 2006) or families of "choice." This ability to bridge together external sources of "identified" family together likely underscores the ability to develop and maintain resilience for many members of the LGBT community. It is important to note that many older LGBT individuals may have mastered coping and management of life situations involving stigma due to repeated encounters, ultimately preparing them to adapt better with the stigmas typically associated with aging (Fullmer, 2006). While exploring some of the issues that may threaten the well-being of older LGBT adults and their health or mental health, it is equally important to assess for areas of strength resulting from such experiences. Such a critical distinction is necessary to underscore, as those faced with adversity often develop significant strengths, resilience, and mechanisms for coping. While such adversity may be expected across the life span, other forms may be sustained or further impacted through rejection, isolation, homophobia, and so on, adding subsequent dimensions of oppression for members of the aging LGBT community.

\section{Sexual Health, Attitudes, and Behavior}

Many older LGBT adults have been sexually active throughout their life, while many remain active, especially with reduced risk of pregnancy and the increased availability of erectile dysfunction medications. However, many professionals assume older LGBT adults are not sexually active, and many sexual health and education campaigns overlook this group (Simone \& Appelbaum, 2008; Emlet, 2004). Older LGBT adults from some age cohorts may find it difficult to volunteer information regarding sexual health or behavior (Emlet, 2004, 2006) due to the sexually repressed or conservative values of the era during which they matured. This is often compounded by attitudes and societal messages often suggesting or assuming that older adults are not or should not be sexual. However, it is important to understand that aging can bring changes that affect sexual arousal and vulnerability to sexually transmitted infections (STIs). Decreased arousal can evoke feelings of insecurity in one partner, with the other partner feeling less attractive as a result. For lesbians or trans-women, thinning of the vaginal walls and decreased or delayed lubrication of the 
vagina increases the risk of tearing, which, combined with decreased immune functioning, places them at risk for STIs (Levy-Dweck, 2005). Social attitudes about masculinity have fueled the popularity of Viagra, resulting in older men having more sexual partners than ever before (LevyDweck, 2005). An education and communication gap between professionals and the aging LGBT community risks not only the opportunity to express affirmation and acceptance of the client's sexual identity but the chance to screen for STIs, including HIV/AIDS; and the opportunity to clearly understand the unique needs of diverse generational cohorts.

The number of deaths among adults ages 65 and older from HIV/AIDS has increased more than any other age group, with African Americans overrepresented in all age groups (Centers for Disease Control, 2012). Many older LGBT adults are not getting voluntarily tested for myriad reasons including stigma surrounding age, sexuality, and HIV status, combined with an overall perceived lack of risk (Emlet, 2004; Simone \& Appelbaum, 2008). Similarly, health care professionals may not consider an older adult to be at risk for HIV and credit its symptoms to the natural weakening of the immune system associated with the aging process (Levy-Dweck, 2005; Simone \& Appelbaum, 2008). As a result, many older adults who are diagnosed with HIV/AIDS are found to have a lower CD4 (T-cell) count than their younger counterparts at time of primary diagnosis, and thus at higher risk for HIV/AIDS-related complications (Simone \& Appelbaum, 2008; Heckman et al., 2001). Ultimately it remains urgent to diagnosis HIV infections at an earlier stage while preventing new infections among this age group, both goals that can be accomplished through education and training for members of the aging LGBT community as well as ongoing professional development for those working in the field of aging. Regardless of HIV status, intervention efforts with members of the aging LGBT community should focus on understanding diverse cultures, norms, lifestyles, and experiences (Strombeck \& Levy, 1998) while building on knowledge gained from effective interventions for behavior change among younger cohorts and sensitivity to sociocultural contexts (Coon, Lipman, \& Ory, 2003). Ultimately, models of healthy sexuality across the life span may be linked with theories related to HIV prevention interventions, as sexual risk behavior impacts a number of older populations typically at higher risk for infection including gay men, heterosexual women, and intravenous drug users (Coon et al., 2003). Notably, there remains a dearth of long-term research and understanding related to the implications of living 20 or more years with HIV/AIDS, whether on highly active antiretroviral therapies (HAART) or not, along with challenges related to physical and mental health outcomes (Burgoyne, Rourke, Behrens, \& Salit, 2004).

It should be noted that not all LGBT individuals in various age cohorts have the same history, experience, or understanding of the impact of HIV/AIDS. Many LGBT older adults who lived through the AIDS epidemic in the 1980s and 1990s may actually be far more cautious of, and educated about, HIV/AIDS and safer-sexual practices and attitudes (Craig, Dentato, Messinger, $\&$ McInroy, 2014) that sets them apart from younger generations who may be complacent and no longer view HIV as a terminal illness (Jaffe, Valdiserri, \& De Cock, 2007) thanks to advancements with HAART and availability of pre-exposure prophylaxis treatments. Older LGBT individuals may be more willing to communicate about their sexual practices and more comfortable engaging in educational discussions. Regardless of age cohort or client population, sex and sexuality are important topics to discuss, as practitioners otherwise risk ignoring vulnerabilities that can have broad reaching implications for physical and emotional health and well-being.

\section{Systemic Challenges}

The aging LGBT community frequently report feeling skeptical of health care professionals (Brotman, Ryan, \& Cormier, 2003) and reluctant to rely on a system historically filled with stigma, discrimination (Deevey, 1990; Jackson, Johnson, \& Roberts, 2008), and oppression based on alleged pathology (Butler \& Hope, 1999; McFarland \& Sanders, 2003). Despite the growing 
acceptance of the LGBT community by society, many direct care organizations and staff members still remain poorly equipped to address the multi-faceted needs of LGBT elderly individuals (Smith et al., 2010; Hughes et al., 2011). Thompson (2008) found that heteronormativity still dominates the medical field, while training among medical and nursing students rarely focuses on addressing the health care concerns of LGBT individuals. Such training may relate to maleto-female transsexuals' need for regular prostate exams or most female-to-male transsexuals' need for regular pap smears (Thompson, 2008). In the same regard, recent literature is just beginning to examine the effective preparedness of LGBT and non-LGBT undergraduate and graduate students within mental health professions, including social work (Logie et al., 2007; Bogo, 2010; Craig et al., 2014), to practice among the LGBT community and other minority populations.

With regard to caregiving facilities, most LGBT individuals entering nursing homes or other care communities are assumed to be heterosexual with genitalia congruent with their presented gender (Persson, 2009). Several studies underscore anxieties about discrimination by caretakers, the resultant negative impact on physical and mental health, and the manner by which older LGBT adults seek care (Logie et al., 2007; Williams \& Freeman, 2007; Stein et al., 2010). For transsexual and transgender individuals, the pathologizing of trans-identities makes health care and health insurance less accessible to the overall community, particularly for those of diverse race/ethnicities, more so than for LGB individuals (Williams \& Freeman, 2007). Anti-LGBT stigma is credited as one of the reasons older adults living with HIV frequently forgo formal treatment for minor health issues, resulting in longer hospital stays when these issues become life-threatening (Heckman et al., 2001). Such systemic challenges remain pervasive yet provide ample opportunity for expanded learning opportunities in the classroom and field placements; to competency trainings within agencies, hospitals and assisted living facilities; and to educating hospice staff members and family caregivers alike.

\section{Policy Issues}

Discussion surrounding the impact of policy issues upon various members of the LGBT community differs significantly between cohorts. Post-Stonewall cohorts have witnessed decades of slow, yet steady progress regarding policy changes, including (1) the inclusion and later removal of homosexuality as a pathology and personality disorder from the American Psychiatric Association's DSM III (Ben-Ari, 2001); (2) exclusion from military service and overturning of the Clinton era "Don't Ask, Don't Tell" policy (Knauer, 2009); (3) the ongoing civil union, domestic partnership, marriage debate; (4) the Obama administration's 2011 refusal to uphold or defend the 1996 Defense of Marriage Act (Elze, 2006; Landau, 2012) in court; and (5) housing and employment discrimination (Cahill \& South, 2002). The evolution of such changes may be associated with the national policy factors previously mentioned; increased media presence of LGBT themes and characters; members of the LGBT community continuing to come out; allies who support LGBT issues or personally know a member of the community (the familiarity factor); or some combination thereof.

Despite these advances, constraints still exist in the cultural and sociopolitical arenas, namely, the lack of equal legal rights and equality for same-sex couples and LGBT individuals at the state and federal levels (Cahill \& South, 2002; Hughes et al., 2011). As of this writing, marriage equality benefits the residents of 12 states in the United States, but the lack of federal recognition places older adults at a severe disadvantage while also providing differences with regard to perception of need for marriage equality among age cohorts (Goldberg \& Kuvalanka, 2012). Regardless of partner status, younger cohorts may assume such legal protection is unnecessary or irrelevant while older cohorts oppositely believe marriage equality is a necessary protection to be guaranteed under law. This is evidenced by the fact that without recognition of same-sex marriage, many LGBT 
individuals with insurance providing partner benefits often end up paying more over time with benefits still taxable as income at the federal level (Patterson, 2009). The lack of LGBT partner recognition via marriage or civil unions may also impact coverage and eligibility for biological or adopted children (Pawelski et al., 2006). Hospitals, particularly those religiously affiliated, still override advanced directives, and families have greater legal pull in contesting wills (Baker, 2009), unless certain property has been directly sold from one partner to another. If an LGBT older adult is predeceased by their partner, access to retirement accounts, property, or Social Security survivor's income may be severely limited (Goffe, 2011), if not entirely unavailable, and survivors with major health needs may find themselves faced with choices surrounding whether to remain at their long-term home or move out and remain eligible for Medicare (Cahill \& South, 2002).

There are national senior living projects under way to create communities that cater specifically to the needs of older LGBT adults, but there is concern that they will be available only to wealthier individuals, underscoring the need for competence in existing organizations as well as non-discriminatory housing legislation to ensure that poor and middle class LGBT individuals do not risk isolation (Cahill \& South, 2002). The Affordable Care Act (ACA) promises greatly improved accessibility to health care and insurance for many older adults, but it will take a while for the Medicare coverage gap to be phased out, which may prevent certain older adults from affording needed medications (Brown \& Mann, 2012). Even with the advent of the ACA, it is not clear that hormones or other transition-related medications and procedures will be covered for transgender and transsexual individuals. Legal experts trained both in elder law and LGBT legal issues are limited and often more accessible in larger cities rather than rural locations. While the fifth edition of the DSM eliminates the diagnosis of gender identity disorder for the more descriptive gender dysphoria, the criteria still pathologize gender nonconforming behavior and rely on rigid behavioral expectations for individuals based on their genitalia. Thus, the need for continued monitoring of policy development and advocacy is necessary to ensure that future policies at the local, state, and federal levels are inclusive of LGBT rights, most especially those of the aging LGBT community.

\section{Implications}

As social workers, practitioners, and health care professionals, it is our mission to ensure that students as well as communities are educated and sensitized to the particular concerns of older LGBT adults (Donahue \& McDonald, 2005). In order to effectively expand cohort-specific knowledge and clarify perceptions of LGBT legal, psychosocial, well aging, and health care issues, educators and practitioners alike must ensure expansion and infusion of such topics within the classroom (Logie et al., 2007; Gezinski, 2009; Craig et al., 2014), agency settings, field placements (Messinger, 2011) and counseling offices alike while measuring competency whenever possible. This may be accomplished though broader and ongoing discussions related to policy, advocacy, social justice, and civil rights in order to effectively advocate and increase knowledge of LGBT aging (McFarland \& Sanders, 2003), lifespan, and psychosocial issues. Across cohorts and communities, there remains need for continued discourse about LGBT issues, most specifically those related to well-aging concerns among older LGBT adults across the life span, and infusion of such content and topics at the undergraduate and graduate levels alike.

\section{Educational Forums}

The importance of public and private educational forums to explore LGBT topics, whether through use of films, guest speakers, or interactive dialogue, to disseminate information and 
expand knowledge should not be understated. To raise awareness of the complexities of aging and age cohort differences facing LGBT older adults, an interactive and didactic event was arranged for students, faculty, and community members at (Loyola University, Chicago). The event was planned to discuss well-aging issues that exist among the older LGBT population through a viewing of the film Gen Silent (Gen Silent, 2011), followed by a panel discussion with the film's director and faculty members. Gen Silent chronicles the stories of six older LGBT adults, couples, and their families and the challenges they experience with health, mental health, and caregiving over the course of a year. This event was held with the purpose of raising awareness among social work students and professionals as well as members of the local community of the prevalent issues faced by aging LGBT adults; to examine differing perceptions among those cohorts present; and to better understand implications for social work education, practice, policy, and continued research in these areas. Opportunities for educational forums and discussions, prompted by use of films such as Gen Silent are necessary to raise awareness and facilitate conversations that may ultimately result in changing attitudes as well as practice behaviors toward older LGBT individuals.

\section{Training}

Mental health professionals should be trained and sensitized to the unique needs of LGBT individuals to empathically assist them with the exploration of personal experiences that have most impacted their identity. A thorough examination and mindfulness of personal assumptions or biases about LGBT aging issues may assist in the creation of a genuine therapeutic alliance with clients. Utilizing affirming models of practice (Chernin \& Johnson, 2003; Crisp \& McCave, 2007) that include a person in environment and strengths perspective will assist with the affirmation of an individual's LGBT identity. Additionally, the use of visible symbols of acceptance, such as a rainbow flag or pink triangle at an agency or office, promotes nonverbal messages of safety and inclusion for members of the LGBT community (Ayres \& Brown, 2011). Regular and ongoing trainings on historical and emergent LGBT issues will assist with educating instructors (Athanases \& Larrabee, 2003) and agency staff members about the health and mental health issues commonly faced by this population as well as with the appropriate language and best practices to utilize. Knowing to ask, and more specifically how to ask, about someone's sexual orientation or preferred gender pronouns will help in creating a welcoming and empathic atmosphere (Chernin \& Johnson, 2003; Crisp \& McCave, 2007) based on understanding and not simply knowledge of correct words or phrases. Revising paperwork and electronic records to be more inclusive of diverse sexualities and gender identities (Richmond, Burnes, \& Carroll, 2012) will also send the message that an organization has awareness and willingness to appropriately serve this population as well as an ability to go above and beyond to meet their unique needs.

Being able to overcome biases about older adult sexuality will also help to provide more effective support. Asking permission to talk about sex with an older adult conveys sensitivity and respect, while placing the control in the hands of the client (Hillman, 2008). When exploring topics related to sexual activity, it is important to avoid conveyance of subtle assumptions (Crisp \& McCave, 2007) that older adults do not, or should not, have sex; therefore asking "how often" rather than "do you" can make a significant difference in the therapeutic alliance. It also creates an opportunity to talk about preferred sexual partners and sexual practices, which will ultimately inform the provision of care. Another systemic intervention that goes beyond typical education and training pertains to consistent recommendation of HIV and other STI tests (Coon et al., 2003; Emlet, 2006) — not currently required by Medicare — to older adults such as any other age group. In terms of HIV and STI prevention, continued development and refinement of safe-sex guidelines and education geared specifically toward older LGBT adult communities (Coon et al., 2003; Emlet, 2004, 2006) is necessary. 


\section{CONCLUSION}

There is strong momentum and incremental change occurring with regard to ensuring equality for all members of the aging LGBT community across generational cohorts. Such progress continues with the Obama administration choosing not to uphold the Defense of Marriage Act (Landau, 2012) and the Supreme Court hearing cases regarding marriage equality for same-sex couples. However, such legislation must not solely enforce tolerance, as continued education and advocacy is essential to effect the slower social changes that bring true acceptance (Donahue \& McDonald, 2005). As such change and education evolves about the impact of policy upon LGBT individuals at the federal, state, local, and organizational levels, advocacy on their behalf will always be needed (Cahill \& South, 2002). The mere fact that research has gone from broader LGBT issues to more specific topics such as LGBT aging is not solely evidence of the growing knowledge base (Fredriksen-Goldsen et al., 2011; Hughes et al., 2011) but relates directly to individual attitudes regarding care and affirmation for this population as part of larger society. Ultimately, such acceptance and visibility will ensure a broader dialogue to explore avenues through which to best meet the needs of older LGBT adults deserving of equal rights and competent care (Stein et al., 2010). Educators, practitioners, and researchers alike would benefit from a broader understanding of specific life span and age cohort differences that exist among the LGBT community (Smith et al., 2010). For this trend to continue in a positive manner, however, it is necessary that professionals prepare themselves to work with LGBT older adults such as any other diverse client population as well as to acknowledge the ongoing need for personal and professional growth (Bogo, 2010; Logie et al., 2007; Craig et al., 2014). Only through continued learning and exploration of personal attitudes and beliefs about LGBT and aging issues can this community be effectively, comprehensively, and competently served.

\section{REFERENCES}

Athanases, S. Z., \& Larrabee, T. G. (2003). Toward a consistent stance in teaching for equity: Learning to advocate for lesbian- and gay-identified youth. Teaching and Teacher Education, 19(2), 237-261.

Atkins, G. L. (2003). Gay Seattle: Stories of exile and belonging. Seattle, WA: University of Washington Press.

Ayres, I., \& Brown, J. G. (2011). Straightforward: How to mobilize heterosexual support for gay rights. Princeton, NJ: Princeton University Press.

Baker, S. S. (2009). Where conscience meets desire: Refusal of health care providers to honor health care proxies for sexual minorities. Women's Rights Law Reporter, 31, 1.

Ben-Ari, A. (2001). Homosexuality and heterosexism: Views from academics in the helping professions. British Journal of Social Work, 31, 119-131.

Berger, R. M. (1984). Realities of gay and lesbian aging. Social Work, 29(1), 57-62.

Berger, R. M., \& Kelly, J. J. (1986). Working with homosexuals of the older population. Social Casework, 67(4), $203-210$.

Bogo, M. (2010). Achieving competence in social work through field education. Toronto, ON: University of Toronto Press, Inc.

Bronfenbrenner, U. (1979). The ecology of human development. Cambridge, MA: Harvard University Press.

Brotman, S., Ryan, B., \& Cormier, R. (2003). The health and social service needs of gay and lesbian elders and their families in Canada. The Gerontologist, 43(2), 192-202.

Brown, R., \& Mann, D. R. (2012, October). Best bets for reducing Medicare costs for dual eligible beneficiaries: Assessing the evidence. Henry J. Kaiser Family Foundation Policy Brief, 1-24.

Burgoyne, R. W., Rourke, S. B., Behrens, D. M., \& Salit, I. E. (2004). Long-term quality-of-life outcomes among adults living with HIV in the HAART era: The interplay of changes in clinical factors and symptom profile. AIDS and Behavior, 8(2), 151-163.

Butler, S. S. (2004). Gay, lesbian, bisexual, and transgender (GLBT) elders: The challenges and resilience of this marginalized group. Journal of Human Behavior in the Social Environment, 9(4), 25-44.

Butler, S. S., \& Hope, B. (1999). Health and well-being for late middle-aged and old lesbians in a rural area. Journal of Gay \& Lesbian Social Services, 9(4), 27-46. 
Cahill, S., \& South, K. (2002). Policy issues affecting lesbian, gay, bisexual, and transgender people in retirement. Generations, 26(2), 49-54.

Centers for Disease Control and Prevention. (2012). Estimated HIV incidence in the United States 2007-2010. HIV Surveillance Supplemental Report, 17(4). Retrieved from http://www.cdc.gov/hiv/topics/surveillance/resources/reports/ \#supplemental.

Chernin, J. N., \& Johnson, M. R. (2003). Affirmative psychotherapy and counseling for lesbians and gay men. Thousand Oaks, CA: Sage.

Clunis, D. M., Fredricksen-Goldsen, K. I., Freeman, P. A., \& Nystrom, N. (2005). Lives of lesbian elders: Looking back, looking forward. Binghamton, NY: The Haworth Press.

Cohen, H. L., Padilla, Y. C., \& Aravena, V. C. (2006). Psychosocial support for families of gay, lesbian, bisexual, and transgender people. In D. Morrow \& L. Messinger (Eds.), Sexual orientation \& gender expression in social work practice: Working with gay, lesbian, bisexual, \& transgender people (pp. 153-176). New York, NY: Columbia Press.

Coon, D. W., Lipman, P. D., \& Ory, M. G. (2003). Designing effective HIV/AIDS social and behavioral interventions for the population of those age 50 and older. JAIDS: Journal of Acquired Immune Deficiency Syndromes, 33, S194-S305.

Craig, S. L., Dentato, M. P., Messinger, L., \& McInroy, L. (2014). Educational determinants of readiness to prcatice with LGBTQ clients: Social work students speak out. British Journal of Social Work. Under review.

Crisp, C., \& McCave, E. L. (2007). Gay affirmative practice: A model for social work practice with gay, lesbian, and bisexual youth. Child and Adolescent Social Work Journal, 24(4), 403-421.

D'Augelli, A. R., \& Grossman, A. H. (2001). Disclosure of sexual orientation, victimization, and mental health among lesbian, gay, and bisexual older adults. Journal of Interpersonal Violence, 16(10), 1008-1027.

Dentato, M. P., Halkitis, P. N., \& Orwat, J. (2013). Minority stress theory: An examination of factors surrounding sexual risk behavior among gay and bisexual men who use club drugs. Journal of Gay and Lesbian Social Services, 25(4), 509-525.

Deevey, S. (1990). Older lesbian women: An invisible minority. Journal of Gerontological Nursing, 16, 35-39.

Donahue, P., \& McDonald, L. (2005). Gay and lesbian aging: Current perspectives and future directions for social work practice and research. Families in Society, 86(3), 359-366.

Dorfman, R., Walters, K., Burke, P., Hardin, L, Karanik, T., Raphael, J., .. Silverstein, E. (1995). Old, sad and alone: The myth of the aging homosexual. Journal of Gerontological Social Work, 24(1/2), 29-44.

Eckenrode, J., \& Gore, S. (1990). (Eds.). Stress between work and family. New York, NY: Plenum

Elder, G. H. (1994). Time, human agency and social change: Perspectives on the life course. Social Psychology Quarterly, 57(1), 4-15.

Elze, D. E. (2006). Oppression, prejudice, and discrimination. In D. Morrow \& L. Messinger (Eds.), Sexual orientation \& gender expression in social work practice: Working with gay, lesbian, bisexual, \& transgender people (pp. 43-77). New York, NY: Columbia Press.

Emlet, C. (2004). HIV/AIDS and aging. Journal of Human Behavior in the Social Environment, 9(4), 45-63.

Emlet, C. (2006). "You're awfully old to have this disease": Experiences of stigma and ageism in adults 50 years and older living with HIV/AIDS. The Gerontologist, 46(6), 781-790.

Floyd, F. J., \& Bakeman, T. S. (2006). Sexual orientation identity formation among gay, lesbian and bisexual youths: Multiple patterns of milestone experiences. Journal of Research on Adolescence, 12(2), 167-191.

Fredriksen-Goldsen, K. I., Kim, H. J., Emlet, C. A., Muraco, A., Erosheva, E. A., Hoy-Ellis, C. P., ... Petry, H. (2011). The aging and health report: Disparities and resilience among lesbian, gay, bisexual, and transgender older adults. Seattle, WA: Institute for Multigenerational Health.

Fredricksen-Golden, K. I., \& Muraco, A. (2010). Aging and sexual orientation: A 25-year review of the literature. Research on Aging, 32(3), 372-413.

Fullmer, E. M. (2006). Lesbian, gay, bisexual, and transgender aging. In D. Morrow \& L. Messinger (Eds.), Sexual orientation \& gender expression in social work practice: Working with gay, lesbian, bisexual, \& transgender people (pp. 286-303). New York, NY: Columbia Press.

Gen Silent. (2011). Movie. Stu Maddox, Director. Retrieved from http://stumaddux.com/GEN_SILENT.html

Gezinski, L. (2009). Addressing sexual minority issues in social work education: A curriculum framework. Advances in Social Work Practice, 10(1), 103-113.

Goffe, W. (2011, April 22). Marriage, domestic partnerships, civil union: The developing tax landscape, through time. Using the law to support LGBT relationships. Washington State Bar Association Qlaw Section CLE, Seattle, WA.

Goldberg, A. E., \& Kuvalanka, K. A. (2012). Marriage (in)equality: The perspectives of adolescents and emerging adults with lesbian, gay, and bisexual parents. Journal of Marriage and Family, 74(1), 34-52.

Gray, H., \& Dressel, P. (1985). Alternative interpretations of aging among gay males. The Gerontologist, $25,83-87$.

Grossman, A. H. (2006). Physical and mental health of older lesbian, gay and bisexual adults. In D. Kimmel, T. Rose, \& S. David (Eds.), Lesbian, gay, bisexual, and transgender aging: Research and clinical perspectives (pp. 53-69). New York, NY: Columbia University Press. 
Heckman, T., Kochman, A., Sikkema, K., Kalichman, S., Masten, J., Bergholte, J., . . Catz, S. (2001). A pilot coping improvement intervention for late middle-aged and older adults living with HIV/AIDS in the USA. AIDS Care, 13(1), $129-139$.

Hillman, J. (2008). Sexual issues and aging within the context of work with older adult patients. Professional Psychology: Research and Practice, 39(3), 290-297.

Hughes, A. K., Harold, R. D., \& Boyer, J. M. (2011). Awareness of LGBT aging issues among aging services network providers. Journal of Gerontological Social Work, 54(7), 659-677.

Jackson, N. C., Johnson, M. J., \& Roberts, R. (2008). The potential impact of discrimination fears of older gays, lesbians, bisexuals and transgender individuals living in small- to moderate-sized cities on long-term health care. Journal of Homosexuality, 54(3), 325-339.

Jaffe, H. W., Valdiserri, R. O., \& De Cock, K. M. (2007). The reemerging HIV/AIDS epidemic in men who have sex with men. JAMA: Journal of the American Medical Association, 298(20), 2412-2414.

Knauer, N. J. (2009). LGBT elder law: Toward equity in aging. Harvard Journal of Law and Gender, 32, 1-58.

Landau, J. (2012). DOMA and presidential discretion: Interpreting and enforcing federal law. Fordham Law Review, 81(2), 619-647.

Levy-Dweck, S. (2005). HIV/AIDS fifty and older. Journal of Gerontological Social Work, 46(2), 37-50.

Logie, C., Bridge, T. J., \& Bridge, P. D. (2007). Evaluating the phobias, attitudes, and cultural competence of master of social work students toward LGBT populations. Journal of Homosexuality, 53(4), 201-221.

McFarland, P., \& Sanders, S. (2003). A pilot study about the needs of older gays and lesbians. Journal of Gerontological Social Work, 40(3), 67-80. doi: 10.1300/J083v40n03_06.

Messinger, L. (2006). A historical perspective. In D. Morrow \& L. Messinger (Eds.), Sexual orientation \& gender expression in social work practice: Working with gay, lesbian, bisexual, \& transgender people (pp. 18-42). New York, NY: Columbia Press.

Messinger, L. (2011). A qualitative analysis of faculty advocacy on LGBT issues on campus. Journal of Homosexuality, 58(9), 1281-1305.

Meyer, I. H. (1995). Minority stress and mental health in gay men. Journal of Health and Social Behavior, 36(March), 38-56.

Meyer, I. H. (2003). Prejudice, social stress, and mental health in lesbian, gay and bisexual populations: Conceptual issues and research evidence. Psychological Bulletin, 129, 674-697.

Moen, P., Dempster-McClain, D., \& Williams, R. M. (1992). Successful aging: A life-course perspective on women's multiple roles and health. American Journal of Sociology, 97, 1612-1638.

Parks, C. A. (1999). Lesbian identity development: An examination of differences across generations. American Journal of Orthopsychiatry, 69(3), 347-361.

Patterson, C. J. (2009). Children of lesbian and gay parents: Psychology, law, and policy. American Psychologist, 64, 727-736.

Pawelski, J. G., Perrin, E. C., Foy, J. M., Allen, C. E., Crawford, J. E., Del Monte, M., ... Vickers, D. L. (2006). The effects of marriage, civil union, and domestic partnership laws on the health and well-being of children. Pediatrics, $118,349-364$.

Persson, D. I. (2009). Unique challenges of transgender aging: Implications from the literature. Journal of Gerontological Social Work, 52(6), 633-646.

Pope, M., \& Schulz, R. (1990). Sexual attitudes and behavior in midlife and aging homosexual males. Journal of Homosexuality, 20(3/4), 169-177.

Reid, J. D. (1995). Development in late life: Older lesbian and gay lives. Lesbian, Gay, and Bisexual Identities over the Lifespan: Psychological Perspectives, 215-240.

Richmond, K. A., Burnes, T., \& Carroll, K. (2012). Lost in translation interpreting systems of trauma for transgender clients. Traumatology, 18(1), 45-57.

Rosenfeld, D. (1999). Identity work among lesbian and gay elderly. Journal of Aging Studies, 13(2), 121-144.

SAGE. (2013). Health, equity and LGBT elder adults of color. Retrieved from http://www.sageusa.org/resources/publications. $\mathrm{cfm}$ ?ID=203

Shankle, M. D., Maxwell, C. A., Katzman, E. S., \& Landers, S. (2003). An invisible population: Older lesbian, gay, bisexual and transgender individuals. Clinical Research \& Regulatory Affairs, 20(2), 159-182.

Simone, M., \& Appelbaum, J. (2008). HIV in older adults. Geriatrics, 63(12), 6-12.

Smith, L. A., McCaslin, R., Chang, J., Martinez, P., \& McGrew, P. (2010). Assessing the needs of older gay, lesbian, bisexual and transgender people: A service-learning and agency partnership approach. Journal of Gerontological Social Work, 53(5), 387-401.

Spencer, C. (1995). Homosexuality in history. New York, NY: Harcourt Brace \& Company.

Stein, G. L., Beckerman, N. L., \& Sherman, P. A. (2010). Lesbian and gay elders and long-term care: Identifying the unique psychosocial perspectives and challenges. Journal of Gerontological Social Work, 53(5), 421-435. 
Strombeck, R., \& Levy, J. A. (1998). Educational strategies and interventions targeting adults age 50 and older for HIV/AIDS prevention. Research on Aging, 20(6), 912-936.

Thompson, E. H. (2008). Do we intend to keep this closested? The Gerontologist, 48(1), 130-132.

U.S. Census Bureau (2010). The Older Population, 2010. Retrieved from www.census.gov/population/www/socdemo/age/ Vaccaro, A. (2009). Intergenerational perceptions, similarities and difference: A comparative analysis of lesbian, gay, and bisexual millennial youth with generation X and Baby Boomers. Journal of LGBT Youth, 6(2-3), 113-134.

Van Wagenen, A., Driskell, J., \& Bradford, J. (2013). "I'm still raring to go": Successful aging among lesbian, gay, bisexual, and transgender older adults. Journal of Aging Studies, 27(1), 1-14.

Weststrate, N. M., \& McLean, K. C. (2010). The rise and fall of gay: A cultural-historical approach to gay identity development. Memory, 18(2), 225-240.

Wethington, E. (2005). An overview of the life course perspective: Implications for health and nutrition. Journal of Nutrition Education and Behavior, 37(3), 115-120.

Whitford, G. (1997). Realities and hopes for older gay males. Journal of Gay \& Lesbian Social Services, 6(1), 79-95.

Williams, M. E., \& Freeman, P. A. (2007). Transgender health. Journal of Gay \& Lesbian Social Services, 18(3-4), 93-108. 